\title{
Clinical Study Role of Toll-Interacting Protein Gene Polymorphisms in Leprosy Mexican Patients
}

\author{
Margarita Montoya-Buelna, ${ }^{1,2}$ Mary Fafutis-Morris, ${ }^{2,3}$ Alvaro J. Tovar-Cuevas, ${ }^{2}$ \\ Anabell Alvarado-Navarro, ${ }^{2,3}$ Yeminia Valle, ${ }^{2}$ Jorge R. Padilla-Gutierrez, ${ }^{2}$ \\ Jose F. Muñoz-Valle, ${ }^{2}$ and Luis E. Figuera-Villanueva ${ }^{4}$ \\ ${ }^{1}$ Centro Universitario de Tonalá, Universidad de Guadalajara, Tonalá, Jal., Mexico \\ ${ }^{2}$ Centro Universitario de Ciencias de la Salud, Universidad de Guadalajara, Guadalajara, Jal., Mexico \\ ${ }^{3}$ CIINDE Universidad de Guadalajara/Instituto Dermatológico de Jalisco "Dr. Jose Barba Rubio", Sierra Mojada 950, \\ Edificio P. Primer Nivel, Colonia Independencia, 44340 Guadalajara, Jal., Mexico \\ ${ }^{4}$ Genetic Division Department, Biomedical Research Center West, Instituto Mexicano del Seguro Social, Sierra Mojada 800, \\ Colonia Independencia, 44340 Guadalajara, Jal., Mexico
}

Correspondence should be addressed to Mary Fafutis-Morris; mfafutis@gmail.com and Luis E. Figuera-Villanueva; luisfiguera@yahoo.com

Received 30 April 2013; Revised 9 September 2013; Accepted 14 September 2013

Academic Editor: Yoshio Ishibashi

Copyright (c) 2013 Margarita Montoya-Buelna et al. This is an open access article distributed under the Creative Commons Attribution License, which permits unrestricted use, distribution, and reproduction in any medium, provided the original work is properly cited.

\begin{abstract}
Background. Leprosy is a debilitating infectious disease of human skin and nerves. Genetics factors of the host play an important role in the disease susceptibility. Toll-interacting protein (TOLLIP) is an inhibitory adaptor protein within the toll-like receptor (TLR) pathway, which recognizes structurally conserved molecular patterns of microbial pathogens, initiating immune responses. The objective of this study was to investigate the association of variants in the TOLLIP gene with susceptibility to leprosy in Mexican patients. Methods. TOLLIP polymorphisms were studied using a case-control design of Mexican patients with lepromatous leprosy (LL). The polymorphisms of TOLLIP at loci -526 C > G (rs5743854), 1309956C>T (rs3750920), 1298430C >A (rs5744015), and 1292831 G>A (rs3750919) were analyzed by PCR, with sequence-specific primers in LL patients and healthy subjects (HS) as controls. Results. Genotype distributions were in Hardy Weinberg equilibrium for all sites except for rs3750920. Neither genotype nor allele frequencies were statistically different between LL patients and controls $(P>0.05)$. The maximum pairwise $D^{\prime}$ coefficient reached was 0.44 of linkage $(P=0.01)$ for all the polymorphisms except for rs5743854. The three loci haplotype comparison yielded no significant differences between groups. Conclusions. Just the individuals with genotype C/C of rs3750920 have a trend of protective effect to developing LL.
\end{abstract}

\section{Background}

Leprosy (L), or Hansen's disease, is a chronic infection caused by the intracellular pathogen Mycobacterium leprae [1]. The registered prevalence globally at the beginning of 2012 was 181,941 leprosy patients [2]. Leprosy is a disease that presents as a spectrum of clinical manifestations that depend on the host cell-mediated immune response against the M. leprae [3]. One end of the disease spectrum, patients with tuberculoid leprosy (TT), shows a strong cellular immune response, resulting in resistance responses that restrict the growth of the pathogen. The number of lesions is few and bacilli rare, although tissue and nerve damage are frequent. At the opposite end of this spectrum, patients with lepromatous leprosy (LL) have a limited cellular immune response, making them susceptible to disseminated infection. Skin lesions are numerous and growth of the pathogen is unabated. The factors that influence which type of leprosy develops are not well understood. Many epidemiological studies, which had the objective of identifying susceptibility genes [4], have shown how host genetic factors play a role in the variability of clinical response to infection caused by $M$. leprae. 
Human toll-like receptors (TLRs) are a family of pattern recognition receptors capable of initiating innate immune responses and influencing subsequent adaptive immune responses [5]. Mycobacterial TLR ligands include molecules of bacterial cell wall components, like that found in $M$. leprae bacilli (lipomannan, lipoarabinomannan, phosphatidylinositol-dimannoside, and a $19-\mathrm{kDa}$ lipoprotein) [6-11]. Their activation in response to microbial infection and inflammation triggers NF- $\kappa \mathrm{B}$ and mitogen-activated proteins kinase (MAPK) signaling and culminates in the induction of host defense genes, including the production of numerous cytokines, chemokines, adhesion molecules, and enzymes. However, excessive and prolonged activation of innate immunity is harmful to the host and may even be fatal [12]. Signaling must therefore be tightly controlled to ensure a beneficial response with the appropriate magnitude and duration. Multiple mechanisms exist to halt IL1RI and TLR signaling pathways, including the activity of several inducible signaling suppressors (i.e., MyD88 and IRAK-M). Toll-interacting protein (TOLLIP) is an adaptor protein and acts as an inhibitory factor in the TLR-signaling cascade; overexpression of TOLLIP impairs IL1RI-, TLR2-, and TLR4-triggered NF- $\kappa \mathrm{B}$ and JNK signaling pathways [12-15]. Following the stimulation of these receptors, TOLLIP associates directly with the cytoplasmic TIR domain $[12,16]$, suppressing the phosphorylation and kinase activity of interleukin-1 receptor associated kinase 1 (IRAK-1) [16], and in this way controls the magnitude of inflammatory response to endotoxin [17].

TOLLIP is therefore thought to function mainly to maintain immune cells in a quiescent state and to facilitate the termination of IL-1R/TLR-induced cell signaling during inflammation via suppression of IRAK-1's activity $[13,16]$. TOLLIP, moreover, deregulated inhibition of this pathway might result in attenuated responses to the proinflammatory cytokines (IL-6 and TNF- $\alpha$ ) suppression of TLR-mediated cellular responses and a role in the leprosy.

Several single-nucleotide polymorphisms in the TLR signaling pathways and their negative regulators genes have been reported to influence the production of inflammatory cytokines and implicated in the pathogenesis of allergic, autoimmune as well as to infectious diseases [18-26]. However, effects of genetic variation in TLRs downstream signaling pathways have not been amply studied yet.

The TOLLIP gene is located on chromosome 11p15 (MIM: 606 277) and comprises 6 exon encoding 274 amino acid transcripts. It is a negative regulator of TLR signaling cascade and was implicated in suppression of the TLR2 [12] and TLR4 pathways [14]. We compared the distribution of four SNPs at TOLLIP gene: $-526 \mathrm{C} / \mathrm{G}$ (rs5743854), exon 4 Pro139Pro (rs3750920), exon 6 Ala222Ser (rs5744015), and $3^{\prime}$ UTR (rs3750919) in a population-based design study of LL Mexican patients.

\section{Methods}

2.1. Patients and Controls. Leprosy patients $(n=93)$ attended in the Instituto Dermatologico de Jalisco (SSA) and took part in this study. All patients were residents in the western of Mexico. They were classified according to clinical and laboratorial (Mitsuda's test and histology exams) observations made by dermatologist responsible for leprosy diagnosis as LL patients, summarized in Table 1.

The control group was composed of 152 healthy individuals of Mexican mestizo ethnicity, selected according to demographic parameters. The mestizo ethnicity is the result of genetic crossing between Spanish and Amerindian people [27] and represents $80 \%$ of the overall population of Mexico [28]. Matching patients minimized the risk of population stratification bias, due to differences in ethnic background between patients and controls, and variations of allele frequencies, according to ethnic background, with control individuals of the same ethnic backgrounds and residence in the same geographical areas of leprosy prevalence. Ethics committee of the Instituto Dermatologico de Jalisco (SSA) approved the study and Declarations of Helsinki protocols were followed. Samples were taken only after participants voluntarily signed an informed consent form. Blood samples were collected from patients and healthy subjects (HS) in ethylenediamine tetra-acetic acid anticoagulant. DNA was extracted using a standard salting-out method [29].

2.2. Genotyping. All four polymorphisms in the TOLLIP gene were genotyped by restriction enzyme digestion (see Table 1). Patient and control samples were amplified using the same primers and conditions as previously described by Schimming et al. [30]. After digestion with the respective enzymes for at least three hours, the fragments were separated on polyacrylamide gel, electrophoresed in $1 \mathrm{X}$ TBE buffer (Native PAGE), and viewed by staining with $0.2 \%$ silver nitrate according to Sanguinetti et al. [31].

2.3. Statistical Analysis. Allele frequency was obtained by direct counting. The agreement of Hardy-Weinberg equilibrium was evaluated using the SAS software v8 (SAS Institute Inc., Cary, NC, USA). Statistical significance was indicated by $P<0.05$. The odds ratios (OR), with $95 \%$ confidence intervals $(95 \% \mathrm{CI})$, were calculated using SISA statistics online (http://home.clara.net/sisa/), to evaluate the risk of the individual developing the disease while having a particular TOLLIP type. Haplotypes frequencies were inferred using EMHAPFREQ software [32]. Pairwise linkage disequilibrium (LD) was expressed as Lewontin's $\mathrm{D}^{\prime}$ corrected coefficient [33]. Comparison data was evaluated by $\chi^{2}$ test or the Fisher exact-test when applicable.

\section{Results}

A total of $98 \mathrm{LL}$ patients were recruited and 152 unrelated otherwise healthy individual as a control. Analysis of genotype and allele frequencies of TOLLIP was done in both groups, summarized in Table 2. In controls genotype distributions were in Hardy Weinberg equilibrium for all sites except for rs3750920 (exon 4).

3.1. Leprosy Susceptibility. To identify a genetic relation between TOLLIP SNPs and lepromatous pole of clinical spectrum of leprosy, four previously published TOLLIP polymorphisms at loci $-526 \mathrm{C}>\mathrm{G}$ (rs5743854), 1309956C>T 
TABLE 1: Clinical and demographic characteristics of patients with LL.

\begin{tabular}{lr}
\hline Characteristic & LL $n=98$ \\
\hline Disease duration (years), mean \pm SD & $10 \pm 7.9$ \\
Age, mean \pm SD & $54.63 \pm 15.92$ \\
Gender & 36 \\
$\quad$ Female (\%) & 62 \\
$\quad$ Male (\%) & 38 \\
Family history (\%) & 100 \\
Bacilloscopy (\%, ++/+++) & 100 \\
Mitsuda test (\%, negatives) & 56 \\
Treatment PCT (\%) & 44 \\
New cases (non-Tx, \%) & \\
\hline
\end{tabular}

Quantitative variables are expressed as means \pm standard deviations (SD) and qualitative variables as frequencies and percentages (\%) as noted. LL: lepromatous leprosy. PCT: polychemotherapy (Rifampin, Clofazimine, Dapsone). Tx: treatment. Family history refers to at least one first grade family who has been infected with leprosy bacillus. Bacilloscopy samples were taken from ear smear.

(rs3750920), 1298430C >A (rs5744015), and $1292831 \mathrm{G}>\mathrm{A}$ (rs3750919) were screened [30]. Our results showed that the genotypes frequencies of tagging SNPs rs5743854 $(P=0.76)$, rs3750920 $(P=0.05)$, rs5744015 $(P=0.76)$, and rs3750919 $(P=0.76)$ were nonsignificant differences of LL patients versus HS. However, in LL patients a decreased frequency in C/C genotype of rs3750920 (25\%), in comparison with HS (37\%), was observed $(P=0.05)$. These trends could suggest a protective effect in western population from Mexico. Also, when we analyzed the allele frequencies no significant differences were found (rs5743854, $P=0.15$; rs3750920, $P=$ 0.09; rs5744015, $P=1.00 ;$ rs 3750919, $P=0.29$ ). The allele and genotype frequencies of the four tagging SNPs in the LL patients and control subjects and the statistical analysis results are listed in Table 2 .

3.2. Haplotype and Linkage Disequilibrium Estimation. Haplotypes were estimated based on the genotype frequencies of the LL patients and control group (Table 3). Regarding to linkage disequilibrium analysis (Table 3 ), only the polymorphisms located at exon 4 , exon 6 , and 3'UTR showed nonrandom segregation, where the maximum $\mathrm{D}^{\prime}$ coefficient reached a moderate value of $\mathrm{LD}(\mathrm{LD}=0.44$, Bonferroni correction $P$ value $=0.01)$ [34]. The haplotype comparison for these linked sites (rs3750920, rs5744015, and rs3750919) showed similar distributions between LL patients and the control group. Conversely, Schimming et al. [30] found linkage evidence between the promoter (rs5743854) and 3'UTR (rs3750919) and other intermediate polymorphisms. Since the chromosomal position of the polymorphisms was tested in this study, we expected similar results; however as it has been described LD is influenced by population type [35] among other factors [34].

\section{Discussion}

In leprosy, a variety of host immune-genetic factors seem to influence subjects' susceptibility to $M$. leprae and disease course. Human regulation and nature of an optimal inflammatory response to $M$. leprae remain poorly understood.
Mycobacterial cell wall contains a number of toll-like receptors (TLRs) ligands, including lipoproteins, mycolylarabinogalactan-peptidoglycan complexes, lipids, and lipoarabinomannan (LAM). Although TLRs are crucial for host defense, it has become apparent that loss of negative regulation of TLR signaling is strongly linked to acute and chronic inflammation, as well as systemic autoimmune diseases [18-25]. In leprosy patients, TLR activation may promote excessive inflammation and apoptosis contributing to pathological signs such as nerve damage [36]. A balance of TLR expression and activation could be crucial to avoid an excessive inflammatory response and lessen disease severity. Negative regulation of TLR-induced response is important for suppressing inflammation and deleterious immune responses. TOLLIP has been identified as a negative regulator that suppresses TLR signaling at multiple levels, and thus high levels could diminish TLR signaling; this phenomenon has been observed in response to pathogen challenge $[13,37,38]$. Some bacterial components stimulate TLR signaling, activating $\mathrm{NF} \kappa \mathrm{B}$, JNK, and p38 signaling cascades, leading to transcription and translation of IL-6 and TNF $\alpha$ [39]. Thus, beneficial or deleterious effects of TOLLIP in leprosy patients depend on expression level and time of exposure to proinflammatory cytokine. It is hypothesized that in leprosy patients high TOLLIP levels could generate a low inflammatory response against mycobacteria; however low TOLLIP levels could produce a sustained inflammatory response which is associated with tissue damage. Screening of TOLLIP gene by sequencing and SSCP analysis $[26,30,40]$ has shown several mutations, which affect gene expression and biological function modifying inflammatory-cytokine production. Therefore, we evaluated whether some of these mutations could influence the susceptibility to LL. We analyze four TOLLIP SNPs, rs5743854 at promoter region, rs3750920 and rs5744015 in the coding region, and rs3750919 at $3^{\prime}$ UTR.

Our study shows that there is no significant association between genotype and allele frequencies of TOLLIP variation -526 G > C (rs5743854) with LL (Table 2). However it has been observed that the same variation of TOLLIP gene showed borderline association with atopic dermatitis, which is a common chronic inflammatory skin disorder. We observed in 
TABLE 2: Genotype and allele distributions of -526 , exon 4, exon 6, and $3^{\prime} U T R$ TOLLIP polymorphisms in LL and HS.

\begin{tabular}{|c|c|c|c|c|}
\hline Polymorphism & $\begin{array}{c}\mathrm{LL}(n=98) \\
n(\%)\end{array}$ & $\begin{array}{c}\text { HS }(n=152) \\
n(\%)\end{array}$ & OR CI (95\%) & $P$ value \\
\hline \multicolumn{5}{|l|}{ rs5743854 } \\
\hline \multicolumn{5}{|l|}{$(-526 \mathrm{C}>\mathrm{G})$} \\
\hline \multicolumn{5}{|l|}{ Genotype } \\
\hline $\mathrm{C} / \mathrm{C}$ & $84(86)$ & $127(84)$ & & \\
\hline $\mathrm{C} / \mathrm{G}$ & $13(13)$ & $22(14)$ & $0.89(0.43-1.87)$ & $P=0.76$ \\
\hline $\mathrm{G} / \mathrm{G}$ & $1(1)$ & $3(2)$ & $0.50(0.05-4.93)$ & $P=0.55$ \\
\hline \multicolumn{5}{|l|}{ Allele } \\
\hline $\mathrm{C}$ & $181(92)$ & $276(91)$ & & \\
\hline G & $15(8)$ & $28(9)$ & $0.82(0.42-0.16)$ & $P=0.54$ \\
\hline \multicolumn{5}{|l|}{$H W E=0.43$} \\
\hline \multicolumn{5}{|l|}{ rs3750920 } \\
\hline \multicolumn{5}{|l|}{$(1309956 \mathrm{C}>\mathrm{T})$} \\
\hline \multicolumn{5}{|l|}{ Genotype } \\
\hline $\mathrm{C} / \mathrm{C}$ & $24(25)$ & $56(37)$ & & \\
\hline $\mathrm{C} / \mathrm{T}$ & $63(64)$ & $83(54)$ & $1.77(0.99-3.16)$ & $P=0.05$ \\
\hline $\mathrm{T} / \mathrm{T}$ & $11(11)$ & $13(9)$ & $1.97(0.772-5.02)$ & $P=0.15$ \\
\hline \multicolumn{5}{|l|}{ Allele } \\
\hline $\mathrm{C}$ & $111(57)$ & $195(64)$ & & \\
\hline $\mathrm{T}$ & $85(43)$ & $109(36)$ & $1.37(0.95-1.98)$ & $P=0.09$ \\
\hline \multicolumn{5}{|l|}{$H W E=0.04$} \\
\hline \multicolumn{5}{|l|}{ rs5744015 } \\
\hline \multicolumn{5}{|l|}{$(1298430 \mathrm{C}>\mathrm{A})$} \\
\hline \multicolumn{5}{|l|}{ Genotype } \\
\hline $\mathrm{C} / \mathrm{C}$ & $96(98)$ & $148(97)$ & & \\
\hline $\mathrm{C} / \mathrm{A}$ & $2(2)$ & $4(3)$ & $0.80(0.14-4.29)$ & $P=0.76$ \\
\hline $\mathrm{A} / \mathrm{A}$ & $0(0)$ & $0(0)$ & $1.54(0.03-78.2)$ & $P=1.00$ \\
\hline \multicolumn{5}{|l|}{ Allele } \\
\hline $\mathrm{C}$ & 194 (99) & 300 (99) & & \\
\hline $\mathrm{A}$ & $2(1)$ & $4(1)$ & $0.77(0.14-4.26)$ & $P=1.00$ \\
\hline \multicolumn{5}{|l|}{$H W E=1.00$} \\
\hline \multicolumn{5}{|l|}{ rs3750919 } \\
\hline \multicolumn{5}{|l|}{$(1292831 \mathrm{G}>\mathrm{A})$} \\
\hline \multicolumn{5}{|l|}{ Genotype } \\
\hline $\mathrm{G} / \mathrm{G}$ & $48(49)$ & $81(53)$ & & \\
\hline $\mathrm{G} / \mathrm{A}$ & $40(41)$ & $62(41)$ & $1.09(0.64-1.86)$ & $P=0.76$ \\
\hline $\mathrm{A} / \mathrm{A}$ & $10(10)$ & $9(6)$ & $1.87(0.71-4.94)$ & $P=0.19$ \\
\hline \multicolumn{5}{|l|}{ Allele } \\
\hline G & $136(69)$ & $224(74)$ & & \\
\hline A & $60(31)$ & $80(26)$ & $1.24(0.83-1.84)$ & $P=0.29$ \\
\hline$H W E=0.81$ & & & & \\
\hline
\end{tabular}

LL: lepromatous leprosy; HS: healthy subjects; OR: odds ratio; C: confidence interval; HWE: Hardy-Weinberg equilibrium $P$ value; codominant model is presented.

healthy heterozygous subjects that genotype rs5743854 G/C showed a similar frequency (14\%) to that reported in Caucasian German control subjects (15.4\%) [30]. Furthermore, allele frequency in our control group (C allele 90\%, A allele $10 \%$ ) showed a similar allele frequency compared to German controls (C allele 92.3\%, A allele 7.7\%).
We observed that rs3750920 C/T genotype was predominant in LL patients (64\%) and controls (54\%); compared to C/C (LL patients (25\%) and controls (37\%)) and T/T (LL patients (11\%) and controls (9\%)) genotypes. Allele C frequency was also more common in LL (57\%) and controls (63\%) groups. Moreover, LL patients showed a decreased 
TABLE 3: Haplotype frequencies of the rs3750920, rs5744015, and rs3750919 TOLLIP polymorphisms in LL and HS.

\begin{tabular}{|c|c|c|c|c|}
\hline Haplotype & $\begin{array}{c}\text { LL }(2 n=196) \\
n(\%)\end{array}$ & $\begin{array}{c}\text { HS }(2 n=304) \\
n(\%)\end{array}$ & $\begin{array}{c}\text { OR } \\
\text { CI }(95 \%) \\
\end{array}$ & $P$ value \\
\hline CCG & $96(48.9)$ & $160(52.7)$ & $*$ & \\
\hline CCA & $15(7.68)$ & $32(10.5)$ & $0.78(0.40-1.52)$ & $P=0.47$ \\
\hline CAA & $0(0)$ & $1(0.002)$ & $0.55(0.02-13.7)$ & $P=0.72$ \\
\hline CAG & $0(0)$ & $2(0.008)$ & $0.33(0.02-7.00)$ & $P=0.48$ \\
\hline TCG & $38(19.4)$ & $61(20.2)$ & $1.03(0.64-1.67)$ & $P=0.88$ \\
\hline TCA & $45(22.9)$ & $47(15.4)$ & $1.59(0.99-2.58)$ & $P=0.06$ \\
\hline TAA & $0(0)$ & $1(0.002)$ & $1.66(0.03-84.5)$ & $P=0.80$ \\
\hline TAG & $2(1.02)$ & $0(0)$ & $8.3(0.40-175)$ & $P=0.17$ \\
\hline
\end{tabular}

LL: lepromatous leprosy; HS: healthy subjects; OR: odds ratio; CI: confidence interval; ${ }^{*}$ Reference haplotype.

frequency in rs3750920 C/C genotype (25\%), in comparison to HS $(37 \%)(P=0.05)$. These tendencies suggest a protective effect to eventually development LL disease (OR 1.77) in Mexican western population. However Shah et al. [26] observed that rs3750920 SNPs were associated with protection from tuberculosis and increased levels of TOLLIP mRNA, and this was the first association of TOLLIP polymorphisms with any infectious disease. These differences could be due to different genetic backgrounds (Amerindians, Spanish, and West African, predominantly) from analyzed subjects, which have different admixture grades depending on Mexico region. Therefore, this genetic heterogeneity (also described as asymmetric admixture) could explain intra- and interpopulation differences in significant gene-diseases associations and prevalence for some diseases. Although the best solution to describe these associations would be the analysis of admixture informative markers (AIMs) to probe the ancestral homogeneity between case and control population samples, a practical solution could be done to demonstrate that the locus of interest has similar allele frequency in parental populations, avoiding population structures problems to achieve convincing inferences.

We also evaluated rs5744015 and rs3750919 polymorphisms variants, and none of them showed significant differences in allelic and genotypic frequencies from patients versus control group. We observed that rs5744015 C/C genotype was predominant in LL patients (98\%) and controls (97\%), compared to C/A (LL patients (2\%) and controls (3\%)) and A/A (LL patients ( $0 \%)$ and controls $(0 \%))$ genotypes. Allele $\mathrm{C}$ frequency was also more common in LL (99\%) and control (99\%) groups. The A/A genotype was not present in patients and controls, which correlates with results found in studies [30] where A/A genotype was also absent in patients and present in $0.5 \%$ in subjects from the control group. Finally for rs3750919 region, G/G genotype was predominant in LL patients (49\%) and controls (53\%), compared to G/A (LL patients (41\%) and controls (41\%)) and A/A (LL patients $(10 \%)$ and controls $(6 \%))$ genotypes. Allele $\mathrm{G}$ frequency was also more common in LL (69\%) and control (74\%) groups. Therefore, G/G genotype frequencies as $G$ allele were the most common in our patients and controls, and these observations were similar to those observed in previous reports on patients with atopic dermatitis [30]. Exhaustive sequencing is required to find or rule out the possibility of an as-yetunknown causal SNP in LL with rs5744015 and rs3750919. Further functional evaluation of novel or associated SNPs is also needed.

Concerning to linkage disequilibrium analysis (Table 3 ), only the polymorphisms located at exon 4 , exon 6 , and $3^{\prime}$ UTR showed nonrandom segregation [34]. The haplotype comparison for these linked sites (rs3750920, rs5744015, and rs3750919) showed similar distributions between LL patients and control group. Therefore even when alleles show linkage disequilibrium this circumstance has no association with risk to develop leprosy in Mexican patients.

The reasons for nonreplication of association studies are numerous and largely reflect inadequate sample sizes, although differences may also be attributed to population stratification, variation in study design, confounding sampling bias, and missclassification of phenotypes. We cannot exclude the possibility that the association result founded for TOLLIP genotype frequencies with LL could be related to other TOLLIP SNPs or neighboring genes not evaluated in this study, which presents LD with this variation. As additional studies, we contemplate including more patients, evaluating cytokine levels (IL-10, TNF- $\alpha$, and IL-6), and mRNA expression of TOLLIP.

Taken together, these findings represent new insights for a better comprehension of negative regulation of TLR4 and TLR 2 signaling pathway and effective mechanisms for therapeutic intervention and treatment of inflammatory diseases. We need to consider the recent and impacting findings reported by Masaki et al., in their in vitro studies where they demonstrate that $M$. leprae is able to induce cellular reprogramming though epigenetics changes, which take part in the migration, plasticity, and immunomodulatory functions, which are finally employed by $M$. leprae to avoid the immune response [41].

\section{Conclusion}

Individuals with genotype $\mathrm{C} / \mathrm{C}$ of rs3750920 have a trend of protective effect to developing LL, and rs5743854, rs5744015, and rs3750919 SNPs are not associated with LL. In the global test haplotypes analyses were not associated with LL risk in Mexican patients. Genetic analysis of genes involved in 
susceptibility to leprosy phenotypes will give us the clues of genetic mechanisms from Mexican leprosy patients and other ethnic or racial backgrounds.

\section{Abbreviations}

$\begin{array}{ll}\text { CI: } & \text { Confidence interval } \\ \text { HS: } & \text { Healthy subjects } \\ \text { IRAK-1: } & \text { Interleukin-1 receptor associated kinase 1 } \\ \text { L: } & \text { Leprosy } \\ \text { LD: } & \text { Linkage disequilibrium } \\ \text { LL: } & \text { Lepromatous leprosy } \\ \text { OR: } & \text { Odds ratio } \\ \text { PAMP: } & \text { Pathogen-associated molecular pattern } \\ \text { PCR: } & \text { Polymerase chain reaction } \\ \text { RFLP: } & \text { Restriction fragment length polymorphisms } \\ \text { SNP: } & \text { Single nucleotide polymorphisms } \\ \text { TLR: } & \text { Toll-like receptor } \\ \text { TOLLIP: } & \text { Toll-interacting protein } \\ \text { TT: } & \text { Tuberculoid leprosy } \\ \text { M. leprae: } & \text { Mycobacterium leprae. }\end{array}$

\section{Conflict of Interests}

The authors declare that there is no conflict of interests regarding the publication of this paper.

\section{Acknowledgments}

The authors thank all patients involved in this research and staff of the Instituto Dermatologico de Jalisco, Dr. Jose Barba Rubio, SSA, for their participation.

\section{References}

[1] I. M. B. Goulart and L. R. Goulart, "Leprosy: diagnostic and control challenges for a worldwide disease," Archives of Dermatological Research, vol. 300, no. 6, pp. 269-290, 2008.

[2] "Global leprosy situation," The Weekly Epidemiological Record, vol. 87, no. 34, pp. 317-328, 2012.

[3] D. S. Ridley and W. H. Jopling, "Classification of leprosy according to immunity. A five-group system," International Journal of Leprosy and Other Mycobacterial Diseases, vol. 34, no. 3, pp. 255-273, 1966.

[4] E. A. Misch, W. R. Berrington, J. C. Vary Jr., and T. R. Hawn, "Leprosy and the human genome," Microbiology and Molecular Biology Reviews, vol. 74, no. 4, pp. 589-620, 2010.

[5] R. Medzhitov, "Recognition of microorganisms and activation of the immune response," Nature, vol. 449, no. 7164, pp. 819826, 2007.

[6] T. K. Means, E. Lien, A. Yoshimura, S. Wang, D. T. Golenbock, and M. J. Fenton, "The CD14 ligands lipoarabinomannan and lipopolysaccharide differ in their requirement for toll-like receptors," Journal of Immunology, vol. 163, no. 12, pp. 67486755, 1999.

[7] H. D. Brightbill, D. H. Libraty, S. R. Krutzik et al., "Host defense mechanisms triggered by microbial lipoproteins through tolllike receptors," Science, vol. 285, no. 5428, pp. 732-736, 1999.
[8] D. M. Underhill, A. Ozinsky, K. D. Smith, and A. Aderem, "Tolllike receptor-2 mediates mycobacteria-induced proinflammatory signaling in macrophages," Proceedings of the National Academy of Sciences of the United States of America, vol. 96, no. 25, pp. 14459-14463, 1999.

[9] S. R. Krutzik, M. T. Ochoa, P. A. Sieling et al., "Activation and regulation of Toll-like receptors 2 and 1 in human leprosy," Nature Medicine, vol. 9, no. 5, pp. 525-532, 2003.

[10] N. Court, S. Rose, M.-L. Bourigault et al., "Mycobacterial PIMs inhibit host inflammatory responses through CD14-dependent and CD14-independent mechanisms," PLoS ONE, vol. 6, no. 9, Article ID e24631, 2011.

[11] P. K. Dagur, B. Sharma, R. Upadhyay et al., "Phenolicglycolipid-1 and lipoarabinomannan preferentially modulate TCR- and CD28-triggered proximal biochemical events, leading to T-cell unresponsiveness in mycobacterial diseases," Lipids in Health and Disease, vol. 11, p. 119, 2012.

[12] Y. Bulut, E. Faure, L. Thomas, O. Equils, and M. Arditi, "Cooperation of Toll-like receptor 2 and 6 for cellular activation by soluble tuberculosis factor and Borrelia burgdorferi outer surface protein a lipoprotein: role of Toll-interacting protein and IL-1 receptor signaling molecules in Toll-like receptor 2 signaling," Journal of Immunology, vol. 167, no. 2, pp. 987-994, 2001.

[13] K. Burns, J. Clatworthy, L. Martin et al., "Tollip, a new component of the IL-1RI pathway, links IRAK to the IL-1 receptor," Nature Cell Biology, vol. 2, no. 6, pp. 346-351, 2000.

[14] T. Li, J. Hu, and L. Li, "Characterization of Tollip protein upon Lipopolysaccharide challenge," Molecular Immunology, vol. 41, no. 1, pp. 85-92, 2004.

[15] W. Piao, C. Song, H. Chen et al., "Endotoxin tolerance dysregulates MyD88- and Toll/IL-1R domain-containing adapter inducing IFN- $\beta$-dependent pathways and increases expression of negative regulators of TLR signaling," Journal of Leukocyte Biology, vol. 86, no. 4, pp. 863-875, 2009.

[16] G. Zhang and S. Ghosh, "Negative regulation of toll-like receptor-mediated signaling by Tollip," The Journal of Biological Chemistry, vol. 277, no. 9, pp. 7059-7065, 2002.

[17] A. Didierlaurent, B. Brissoni, D. Velin et al., "Tollip regulates proinflammatory responses to interleukin-1 and lipopolysaccharide," Molecular and Cellular Biology, vol. 26, no. 3, pp. 735742, 2006.

[18] W.-Q. Song, H.-H. Li, H.-B. Chen, J.-S. Yuan, and X.-J. Yin, "Relationship between polymorphism sites of IRF5, TLR-9 and SLE patients in Shandong Han population," Zhonghua Yi Xue Za Zhi, vol. 89, no. 43, pp. 3038-3042, 2009.

[19] D. N. Cook, J. W. Hollingsworth II, and D. A. Schwartz, "Tolllike receptors and the genetics of innate immunity," Current Opinion in Allergy and Clinical Immunology, vol. 3, no. 6, pp. 523-529, 2003.

[20] A. Soylu, S. Kizildağ, S. Kavukçu et al., "TLR-2 Arg753Gln, TLR-4 Asp299Gly, and TLR-4 Thr399Ile polymorphisms in Henoch Schonlein purpura with and without renal involvement," Rheumatology International, vol. 30, no. 5, pp. 667-670, 2010.

[21] S. Pandey, R. D. Mittal, M. Srivastava et al., "Impact of Tolllike receptors [TLR] 2 (-196 to -174 del) and TLR 4 (Asp299Gly, Thr399Ile) in cervical cancer susceptibility in North Indian women," Gynecologic Oncology, vol. 114, no. 3, pp. 501-505, 2009.

[22] E. G. Pamer, "TLR polymorphisms and the risk of invasive fungal infections," The New England Journal of Medicine, vol. 359, no. 17, pp. 1836-1838, 2008. 
[23] P.-Y. Bochud, T. R. Hawn, M. R. Siddiqui et al., “Toll-like receptor 2 (TLR2) polymorphisms are associated with reversal reaction in leprosy," Journal of Infectious Diseases, vol. 197, no. 2, pp. 253-261, 2008.

[24] P.-Y. Bochud, J. W. Chien, K. A. Marr et al., "Toll-like receptor 4 polymorphisms and aspergillosis in stem-cell transplantation," The New England Journal of Medicine, vol. 359, no. 17, pp. 1766$1777,2008$.

[25] N. W. J. Schröder, C. Hermann, L. Hamann, U. B. Göbel, T. Hartung, and R. R. Schumann, "High frequency of polymorphism Arg753Gln of the Toll-like receptor- 2 gene detected by a novel allele-specific PCR," Journal of Molecular Medicine, vol. 81, no. 6, pp. 368-372, 2003.

[26] J. A. Shah, C. Vary, T. H. Chau et al., "Human TOLLIP regulates TLR2 and TLR4 signaling and its polymorphisms are associated with susceptibility to tuberculosis," The Journal of Immunology, vol. 189, no. 4, pp. 1737-1746, 2012.

[27] C. Gorodezky, C. Alaez, M. N. Vázquez-García et al., "The genetic structure of Mexican Mestizos of different locations: tracking back their origins through MHC genes, blood group systems, and microsatellites," Human Immunology, vol. 62, no. 9, pp. 979-991, 2001.

[28] I. Silva-Zolezzi, A. Hidalgo-Miranda, J. Estrada-Gil et al., "Analysis of genomic diversity in Mexican Mestizo populations to develop genomic medicine in Mexico," Proceedings of the National Academy of Sciences of the United States of America, vol. 106, no. 21, pp. 8611-8616, 2009.

[29] S. A. Miller, D. D. Dykes, and H. F. Polesky, "A simple salting out procedure for extracting DNA from human nucleated cells," Nucleic Acids Research, vol. 16, no. 3, p. 1215, 1988.

[30] T. T. Schimming, Q. Parwez, E. Petrasch-Parwez, M. Nothnagel, J. T. Epplen, and S. Hoffjan, "Association of toll-interacting protein gene polymorphisms with atopic dermatitis," $B M C$ Dermatology, vol. 7, article 3, 2007.

[31] C. J. Sanguinetti, E. D. Neto, and A. J. G. Simpson, "Rapid silver staining and recovery of PCR products separated on polyacrylamide gels," BioTechniques, vol. 17, no. 5, pp. 914-921, 1994.

[32] L. Excoffier and M. Slatkin, "Maximum-likelihood estimation of molecular haplotype frequencies in a diploid population," Molecular Biology and Evolution, vol. 12, no. 5, pp. 921-927, 1995.

[33] R. C. Lewontin, "The Interaction of Selection and Linkage. Ii. Optimum Models," Genetics, vol. 50, pp. 757-782, 1964.

[34] E. Lander and L. Kruglyak, "Genetic dissection of complex traits: guidelines for interpreting and reporting linkage results," Nature Genetics, vol. 11, no. 3, pp. 241-247, 1995.

[35] K. L. O'Connor, C. R. Hill, P. M. Vallone, and J. M. Butler, "Linkage disequilibrium analysis of D12S391 and vWA in U.S. population and paternity samples," Forensic Science International, vol. 5, no. 5, pp. 538-540, 2011.

[36] R. B. Oliveira, M. T. Ochoa, P. A. Sieling et al., "Expression of toll-like receptor 2 on human schwann cells: a mechanism of nerve damage in leprosy," Infection and Immunity, vol. 71, no. 3, pp. 1427-1433, 2003.

[37] G. Melmed, L. S. Thomas, N. Lee et al., "Human intestinal epithelial cells are broadly unresponsive to toll-like receptor 2-dependent bacterial ligands: implications for host-microbial interactions in the gut," Journal of Immunology, vol. 170, no. 3, pp. 1406-1415, 2003.

[38] J.-M. Otte, E. Cario, and D. K. Podolsky, "Mechanisms of cross hyporesponsiveness to toll-like receptor bacterial ligands in intestinal epithelial cells," Gastroenterology, vol. 126, no. 4, pp. 1054-1070, 2004.
[39] S. Akira and K. Takeda, "Toll-like receptor signalling," Nature Reviews Immunology, vol. 4, no. 7, pp. 499-511, 2004.

[40] Z. Song, J. Yin, C. Yao et al., "Variants in the Toll-interacting protein gene are associated with susceptibility to sepsis in the Chinese Han population," Critical Care, vol. 15, no. 1, article R12, 2011.

[41] T. Masaki, J. Qu, J. Cholewa-Waclaw, K. Burr, R. Raaum, and A. Rambukkana, "Reprogramming adult Schwann cells to stem cell-like cells by leprosy bacilli promotes dissemination of infection," Cell, vol. 152, no. 1, pp. 51-67, 2013. 


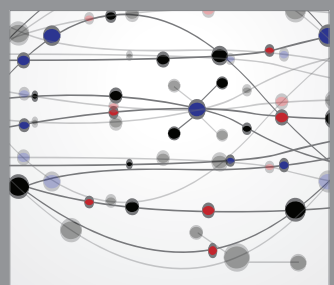

The Scientific World Journal
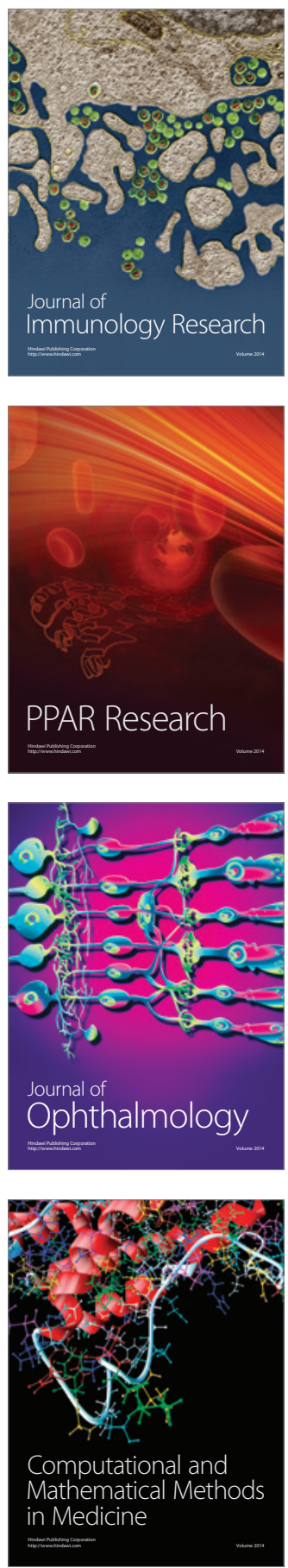

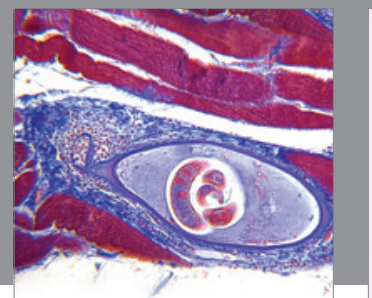

Gastroenterology

Research and Practice
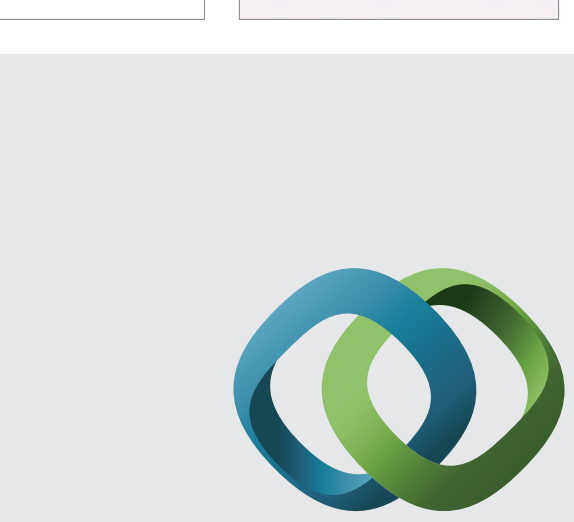

\section{Hindawi}

Submit your manuscripts at

http://www.hindawi.com
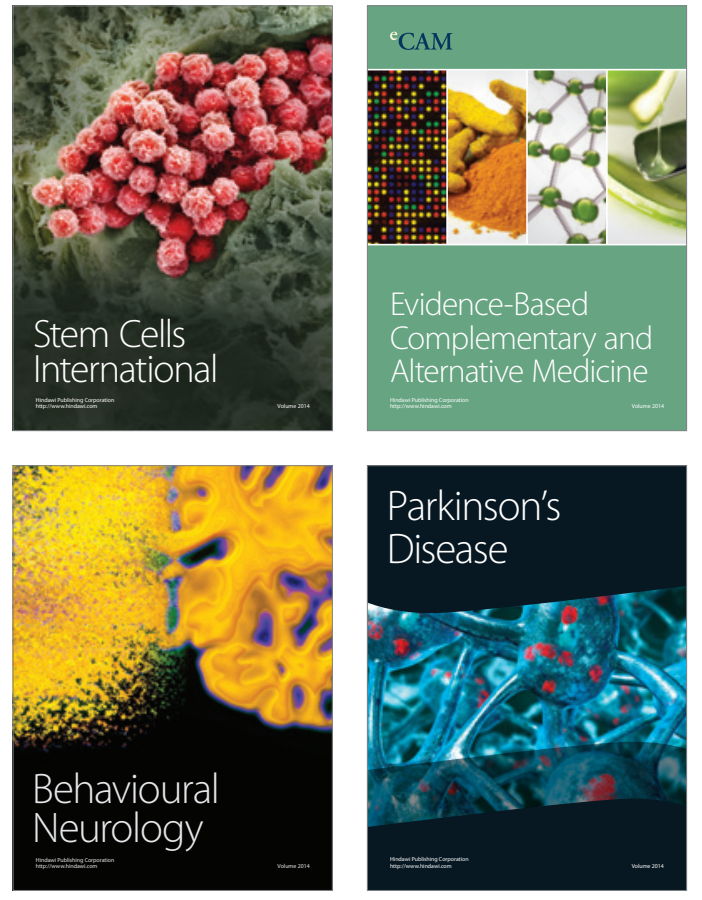
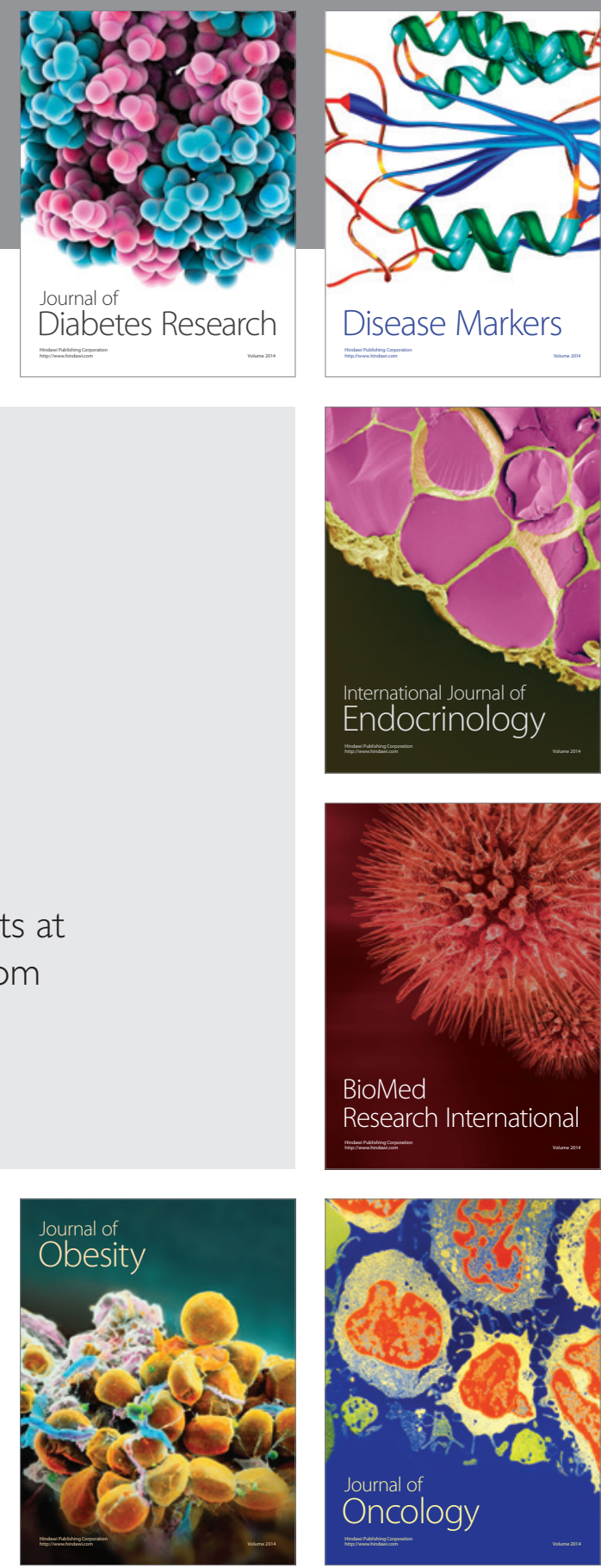

Disease Markers
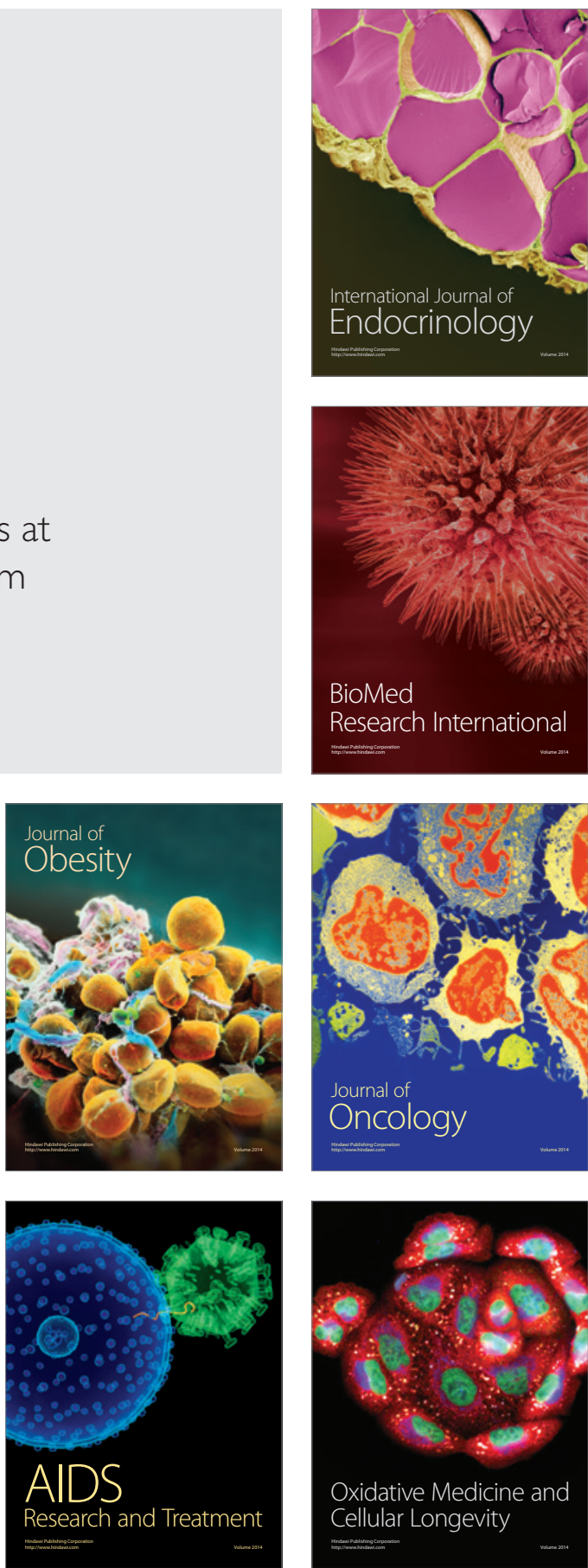